EXERCISE PHYSIOLOGY

\title{
AT A GLANCE
}

\author{
by A. J. van Rensburg M.S.C.
}

\section{INTRODUCTION}

Exercise is fundamental to a healthy existence: Carlsten and Grimby ${ }^{2}$ have been concerned with this aspect of exercise physiology and they state that:

"Regular exercise as leisure activity is needed by every individual.' This statement applies also to the majority of sick people. Exercise programmes must be rendered attractive so as to motivate individuals and groups. Every physician should feel a responsibility towards the establishment and maintenance of an appropriate physical working capacity of his patients."

And, the very last sentence in their book reads as follows:

"The therapeutic scope of exercise in the medical rehabilitation of these patients is very great indeed."

Assuming that this concluding statement is correct, then it follows that a knowledge of exercise physiology should extend the scope, and increase the effectiveness of therapeutic exercise. The purpose of this article is therefore to present some of the basic, and well established concepts of exercise physiology. The first of these is the concept of an individual's physical work capacity.

\section{MAXIMUM OXYGEN CAPACITY (max. cap.)}

It is well known that the harder a person exercises the more oxygen he consumes. This increase in oxygen consumption with exercise load does not continue indefinitely, as, a point is reached when the oxygen con-

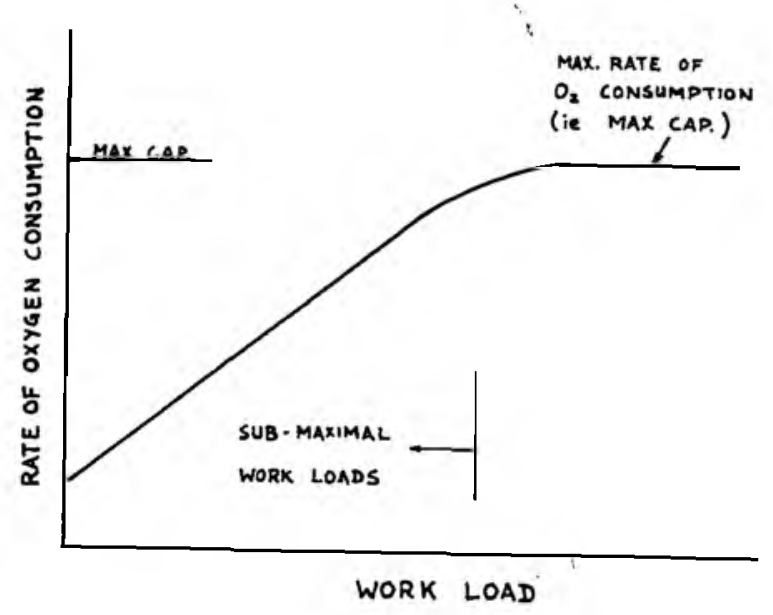

FIG. 1 sumption does not increase with further increases in exercise load. This level of oxygen consumption is known as the individual's maximum oxygen consumption, or his maximum aerobic capacity. The concept is described graphically in Fig. 1. Max Cap. is therefore the maximum amount of oxygen an individual can utilize per minute.

An analogous relationship exists between exercise load and heart rate. This latter relationship forms the basis of various tests which may be used to indirectly determinf an individual's maximum oxygen consumption. This capacity largely determines tine physical working capacity
of an individual.

\section{DETERMINATION OF MAXIMUM OXYGEN CON- SUMPTION}

For an accurate determination of maximum oxygen consumption, it is best to use a direct method. However, this may not always be possible as a well equipped laboratory is essential. A disadvantage of the direct methods is that they are not suited to testing large numbers of people in a short time. Furthermore, it is not possible to use these methods on incapacitated individuals.

Briefly, the direct metnods require an individual to exercise at progressively higher work rates until a level is reached at which:

(a) a further increase in the rate of work does not produce a significant increase in the rate of oxygen consumption,

(b) the time for onset of acute fatigue is short, and

(c) the concentration of lactic acid in the bloq rises sharply.

The exercise is usually performed on a treadmill or bicycle ergonometer. These methods have been described in detail by Wyndham et al. ${ }^{10}$

The direct methods are less accurate but more versatile and convenient. The indirect methods may be classified according to tine physiological parameters upon which they are based. These are listed below:

(a) heart rate (maximum)

(b) respiratory quotient (in excess of 1)

(c) rate of respiratory ventilation (deviation from normal), and

(d) arterial blood analysis: changes in the levels of lactic acid, blood $\mathrm{pH}$, partial pressure of oxygen and partial pressure of carbon dioxide in the blood.

for example, the indirect test based on heart rate makes use of the correlation which exists between an individual's maximum oxygen consumption and the heart rate which is measured after ten minutes of exercise of a particular intensity. Further details may be obtained from papers by Wyndham ${ }^{8,9}$ and by Maritz et al. ${ }^{4}$ 


\section{PHYSIOLOGICAL RESPONSE (STRAIN) TO EXER- CISE}

The physiological strain of exercise is better correlated with the relative oxygen consumption than with the wholute oxygen consumption. Relative oxygen consumption is usually expressed as a percentage of an individual's maximum oxygen consumption.

For those types of exercise requiring endurance, e.g. mathon running, a high maximum oxygen consumption mara basic requirement. A high capacity for consuming is a ben will allow an athlete to perform well at a relatively lower percentage of his maximum capacity. He is therefore under less p'y ysiological strain than a person exerfor at the same rate but having a lower maximum capacity. For a particular rate of exercise, a person with a ingh max cap. will therefore be less susceptible to a tigue than his fellow with a lower max cap.

It is said that a normal individual should never be required to work at $50 \%$ or more of his max cap. for requ extended period of time as this would lead to undue tigue. Therefore, as hard physical work requires an bxygen consumption of 1,5 litres per minute, this type of work siould not be undertaken for long periods by persons having a maximum oxygen consumption of less than 3 litres per minute. A similar consideration would apply to a programme of exercise. Clearly therefore, from the point of view of accomplishing hard work, or hig' levels of exercise, an individual having a low max cap. is at a definite disadvantage. This can be partly neutralized by training i.e. by improving an individual's level of fitness.

\section{LACTATE (LACTIC ACID) TURNPOINT}

The lactate turnpoint is a concept which gives an indication of an individual's level of fitness.

It is known that as the intensity of exercise increases, the lactate concentration in the arterial blood remains, at first, essentially constant, i.e., enough oxygen is being supplied to the working muscles (aerobic metabolism). However, eventually a point is reached where the supply of oxygen to the working muscles is insufficient and the concentration of lactic acid in the arterial blood increases sharply, (anaerobic metabolism). The concept is illustrated graphically in Fig. 2.

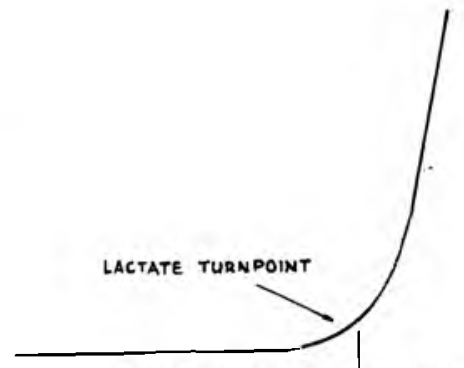

AEROBIC METABOLISM — MNAEROBIC METABOLISM

PERCENT OF MAX. $\mathrm{O}_{2}$ CONSUMPTION
When an individual exercises at a level below this turnpoint, he should be able to work for extended periods of time. Above this turnpoint his endurance capacity falls off rapidly and the individual will experience fatigue due to anaerobic metabolism. Through training, it is possible to move this turnpoint to the right thereby extending the scope of aerobic metabolism. ${ }^{7}$

A sedentary individual will usually have a lactate turnpoint which occurs at less than $40 \%$ of his max cap: a very highly trained athlete can have a turnpoint occurs at $90 \%$ of his max cap.

\section{BED REST}

Max cap. and lactate turnpoint are both adversely affected by inactivity, such as the bed rest which follows an injury or other illness. Return to previous levels is fairly rapid, depending on the period of inactivity and t.:e subsequent exercise programme.

\section{BLOOD FLOW}

Exercise will cause substantial changes in blood flow. These changes are discussed in detail by Carlsten and Grimby $^{2}$ and by Shepherd. ${ }^{5}$ The principal effects of exercise on blood flow are summarised below:

\section{(a) Skin blood flow}

It is important to note that there are basic differences between the control mechanisms of the skin blood flow in general, and that which. occurs in the hands and feet. The central nervous control of the circulation in the hands, feet, ears and lips is mediated by vasoconstrictor fibres of the sympathetic nervous system. Central control of the vessels elsewhere, i.e., in most of the body integument, in the skin of the cheeks, trunk and proximal parts of the limbs, is mediated in the main by the sympathetic "vasodilator" fibres. Evidence suggests that these vasodilator fibres are the sympathetic fibres which supply the sweat glands (Bradykinin mechanism). This difference may, at times, have significant implications.

In hot environments skin blood flow plays a major role in the thermoregulation of an individual, exercising or at rest. At air temperatures below 19 degrees centigrade, skin blood flow plays no role in the thermoregulation of a resting individual.

During exercise the major changes which occur in skin blood flow are ${ }^{6}$ :

1. at the onset of exercise, an immediate reduction in the skin blood flow,

2 . as body temperature begins to increase (as a result of the exercise) there is a corresponding increase in the skin blood flow,

3. when body temperature stabilises the skin blood flow also stabilises, but at a new increased level, and

4. ultimately, there is a phase of decreasing blood flow (at least in the hand) in response to the higher demands of the working muscles for more oxygen.

It is important to note that the blood flow through the skin depends on body temperature ${ }^{1}$ while the flow of blood through the muscles depends on the rate of exercise. (Note: Donald et $\mathrm{al}^{3}$ have shown a decreased skin blood flow to be associated with rheumatic heart disease.)

(b) Muscle blood flow

Physically, blood flow through muscle is more complex than that which occurs through the skin. During muscle contraction the arterial blood flow is decreased, the stronger the contraction the less the flow. The inflow of arterial blood to the muscle increases during muscle relaxation. Conversely, venous outflow is enhanced by muscle contraction (the well known muscle pump). The net result of a cycle of muscle contraction and relaxation is an increase in blood flow through the working muscle. 


\section{CONCLUSION}

This article provides a brief glance at the subject of exercise physiology. Its purpose has been to introduce a few of the fundamental concepts in exercise physiology, to those who have not previously studied the subject.

\section{REFERENCES}

1. Barcroft, H., K. D. Bock, H. Hensei and A. H. Kitchen.

Die Muskeldurchblutung des Menschen bei indirekter Erwärming und Abkühlung. Pflügers. Arch. 261: 199-210, 1955.

2. Carlsten, A. and G. Grimby.

The circulatory response to muscular exercise in man. Charles C. Thomas lllinois and Florida, U.S.A. 1966 .

3. Donald, K. W., J. M. Bishop and O. L. Wade. Changes in the oxygen content of axillary venous blood during leg exercise in patients with rheumatic heart disease. Clin. Sci. 14: 531, 1955.

4. Maritz, J. S., J. F. Morrison, J. Peter, N. B. Strydom and $\mathbf{C}$. $\mathbf{H}$. Wyndham.

A practical method of estimating an individual's maximal oxygen intake. Ergonomics 4: 97-122, 1961.
5. Shepherd, J. T.

The physiology of the circulation in human limbs in health and disezse. $\bar{V}$. B. Saunders Company, Philadelphia and London, 1963.

6. van Rensburg, A. J.

Peripheral blood flow at different levels of exercise M.Sc. Thesis. Potchefstroom University for C.H.E. 1971.

7. Williams, C. G., C. H. Wyndham, R. Kok and M. J. E. von Rahden.

Effect of training on maximum oxygen intake and on anaerobic metabolism in man. Arbeitsphysiol. 24: 18-23, 1967.

8. Wyndham, C. H.

Submaximal tests for estimating maximal oxygen intake. Can. Med. Ass. J. 96: 736-742, 1967.

9. Wyndham, C. H., N. B. Strydom, C. H. van Graan, A. J. van Rensburg, G. C. Rogers, J. S. Greyson and W. H. van der Walt.

Walk or jog for health 11: Estimating the maximum aerobic capacity for exercise. S.A. Med. J. 45: 53-576 1971.

10. Wyndham, C. H., N. B. Strydom, C. G. Williams, A. Munro and A. Heyns. Comparison of estimates of maximum oxygen intake obtained from a treadmill, a bicycle ergonometer and a step test. International Sympos. on Environmental physiol. Kyoto, Japan, 170-182, 1965.

\section{VACANCY}

\section{PROVINCIAL ADMINISTRATION OF THE CAPE OF GOOD HOPE HOSPITALS DEPARTMENT}

Applications are invited from suitably qualified candidates for appointment to the following vacant posts at the:

\section{CONRADIE HOSPITAL, PINELANDS}

Post: Senior Physiotherapist.

Salary: The minimum commencing salary is R3 840 per annum.

*Post: Physiotherapist.

Salary: The minimum and maximum commencing salary is R3 000/3 660 per annum.

Qualifications: Qualification in Physiotherapy acceptable to the South African Medical and Dental Council.

In addition to the salary shown, subject to compliance with certain conditions, the successful applicants are entitled to an annual travel concession, medical aid scheme and holiday and sick leave privileges.

Application should be made on the prescribed form (Staff 23) in duplicate, which is obtainable from the Director of Hospital Services, P.O. Box 2060, Cape Town 8000, or from the Medical Superintendent of any provincial hospital in the Cape Province.

*Applications should be forwarded to the Medical Superintendent of the hospital concerned.

Unless otherwise stated, applications should be forwarded to the Director of Hospital Services at the above address.

The closing date for the receipt of application is 17 September, 1976. 